\title{
On Destination Logo: A Design Review of Visit Malaysia Year's Logo (1990 -2020)
}

\author{
ShawHong SER \\ Department of Communication Management, Faculty of Communication Arts, Chulalongkorn University \\ Bangkok 10330, Thailand. \\ shaw.h@chula.ac.th \\ *Correspondence: shaw.h@chula.ac.th
}

\begin{abstract}
Similar to companies and organizations across the globe, countries as well engage in branding strategies to establish a brand identity and to be positioned as major tourist destinations. Thereupon, the destination logo as one of the most significant elements of a country's branding has become an important subject for brand design and communication research. In this paper, to respond to the research scholarly interest in communication design, the researcher has made an attempt to provide a design review of Malaysia's destination logo from 1990 to 2020. Based on destination logos employed by Malaysia Tourism Promotion Board, the researcher examined how different logos have been designed to represent Malaysia as an outstanding tourism destination along with the development of the "Visit Malaysia Year" (VMY) tourism campaigns. In total, eight logos of "VMY" were reviewed based on their intellectual unity and visual unity. On the intellectual unity aspect, the subject matter of each logo was discussed, and on visual unity features, design elements such as logo style, visual representation, graphic elements, and colors selection were examined. As aforementioned, this paper will provide insights into an understanding of the design and development of destination logos in Malaysia.
\end{abstract}

Keywords: Destination logo, destination branding, communication design, visual identity, Malaysia tourism.

\section{INTRODUCTION}

Since the 1980s, the tourism industry has been identified as one of the key economic development contributors of Malaysia. Thusly, in 1987, the Ministry of Culture and Tourism was established to be in charge of promoting tourism domestically and internationally ("History of MOTAC", 2019). Government agency that was formerly responsible for the nation's tourism development, such as The Tourism Development Corporation of Malaysia (established in 1972) was strategically merged under this new ministry and renamed as Malaysia Tourism Promotion Board (MTPB) to boot Malaysia as an outstanding tourist destination. In 1992, the Ministry of Culture and Tourism was reorganized, and the new Ministry of Culture, Arts and Tourism (MOCAT) was established. In 2018, under the Eleventh Malaysia Plan (11MP), the MOCAT was restructured and become the Ministry of Tourism, Arts and Culture Malaysia (MOTAC) to better serve the close connection between tourism and culture in efforts to promote Malaysia tourism ("History of MOTAC", 2019).

Today, after decades of tremendous effort, Malaysia has become one of the world's most popular tourist destinations. In 2017, the World Economic Forum (WEF) placed Malaysia in the 26th spot (out of 136 countries) in the Travel and Tourism Competitiveness Report (Francis Dass, 2017). In 2018, Malaysia ranked the third most popular Asian travel destination after Japan and Thailand (Fadzly Hanaffi, 2019). Meanwhile, Malaysia also ranked as the first tourist destination by the Global Muslim Travel Index in 2018 (Bernama, 2019). As reported by Datuk Seri Ismail bin Bakar (Chief Secretary to the Government of Malaysia), "indisputably, Malaysia has proven its ability in the tourism industry by consistently being in the top 10 tourism destination and overall dominating ways to generate income for the nation. Tourism is now one of the major contributors to Malaysia's economic 
success" (Janice Tan, 2019).

In 1990, with the theme "Fascinating Malaysia. Year of Festivals", the campaign was a huge success with Malaysia receiving 7.4 million in tourist arrivals compared to 4.8 million in 1989. In 1994, five years after the huge success, a new campaign with a theme, "Fascinating Malaysia. Naturally More" was launched to stimulate the nation's tourism industry. The second campaign was another great success with a total achieved 10.22 million in tourist arrivals (MTPB, 2014). From 1999 to the present, the slogan of "Malaysia Truly Asia" has been used as an official theme of Malaysia's tourism promotions worldwide. The campaign was considered largely successful in the past 20 years, as the nation charted a steady and tremendous growth in tourist arrivals and tourist receipts each year. For instance, as reported by Malaysia Tourism Promotion Board, in 2018, with a total of 25.8 million of international tourist arrivals, Malaysia was ranked 3rd in the most visited Asian country by World Tourism Consultancy IPK International (MTPB, 2019). Meanwhile, tourist receipts also grew by $2.4 \%$, a total of RM 84.1 billion (USD 20.7 billion) in 2018 (Bernama News, 2019). For domestic tourism performance in 2018, the number of domestic tourists showed a double-digital growth of $10.9 \%$, recording a total of 78.2 million domestic tourists as compared to 70.5 million in 2018 (MTPB, 2019). In brief, throughout these years, contribution of the tourism industry to GDP (Gross Domestic Product) for Malaysia was steady, for example, total GDP contributed by the tourism industry was $14.3 \%$ in $2014,13.5 \%$ in $2015,13.9 \%$ in $2016,13.6 \%$ in 2017 and $13.3 \%$ in 2018 (Malaysia Economy Report, 2018).

In 2019, from January to September, Malaysia welcomed 20.1 million $(20,109,203)$ international visitors, a $3.7 \%$ growth compared to the same period in 2018. Meanwhile, tourism performance grew in terms of per capita expenditure, rising by $3.1 \%$ to RM3,289.3 while the average length of stay climbed by 0.1 nights to 7.4 nights. For the year 2020, Malaysia aims to see 30 million international tourist arrivals and bring in total tourist receipts of RM100 billion (Chester Chin,2019). With the positive growth in the tourism industry, hopefully, the upcoming "Visit Truly Asia Malaysia 2020" campaign will continue to be another success. As of today, the tourism industry has become one of the significant contributors to Malaysia's economic development, job creation, and foreign exchange earnings.

\section{The Development of "Visit Malaysia Year" Tourism Campaign (1990-2020)}

The "Visit Malaysia Year" (VMY) is a tourism campaign with a series of events held from time to time to highlight the best of what Malaysia has to offer as a prominent tourist destination in Asia. According to Malaysia Tourism Promotion Board (2020), since 1990, there are five editions of VMY have been developed.

Table 1. Visit Malaysia Year Tourism Campaign

\begin{tabular}{cclc}
\hline \multicolumn{3}{c}{ Visit Malaysia Year Tourism Campaign } \\
\hline & Year & Theme & Tourist Arrivals \\
\hline 1 & 1990 & "Fascinating Malaysia. Year of Festivals" & 7.4 million \\
\hline 2 & $\mathbf{1 9 9 4}$ & "Fascinating Malaysia. Naturally More” & $\mathbf{1 0 . 2 2}$ million \\
\hline 3 & $\mathbf{2 0 0 7}$ & "Malaysia Truly Asia - Celebrating 50 Years of Nationhood" & $\mathbf{2 0 . 9 7}$ million \\
\hline 4 & $\mathbf{2 0 1 4}$ & "Celebrating 1Malaysia Truly Asia" & $\mathbf{2 8}$ million \\
\hline 5 & 2020 & "Visit Truly Asia Malaysia" & 30 million (expected) \\
\hline \multicolumn{5}{c}{ Source: Visit Malaysia Year Tourism Campaign@ Malaysia Tourism Promotion Board, 2020 } \\
\hline
\end{tabular}

As listed above, throughout the four VMY campaigns, the number of tourists visiting Malaysia increased from 7.4 million in 1990 to 28 million in 2014. The results indicated that VMY campaigns were successful events to boost Malaysia's tourism development. Meanwhile, apart from the five VMY campaigns, since 1999, under the theme "Malaysia Truly Asia", various tourism theme-oriented campaigns have also been strategically implemented annually by Malaysia Tourism Promotion Board to promote Malaysia as one of the tops destinations in Asia. For example, in 2015, the Malaysia Year of Festivals (MyFEST) campaign was introduced to ensure that the Malaysian tourism industry remains robust after the Visit Malaysia Year 2014 campaign. From 2010 to 2018, "1Malaysia Contemporary Art Tourism" (1MCAT) campaign was launched annually to promote Malaysia as an art destination for more high-yield tourists. Furthermore, there is a mega-event such as "Art Expo Malaysia" (AEM) to boost Malaysia's art tourism, and Kuala Lumpur Biennale (KL Biennale) to position Malaysia as a destination of creative tourism. For the domestic market, since 1990s, "Cuti-Cuti Malaysia" (Holidays in Malaysia) has been the theme to promote and develop local-based tourism. In 2008, "The Zoom! Malaysia" campaign was another campaign that intensively promoted to encourage Malaysians to look at Malaysia with a fresh perspective and give priority to local holiday destinations (MTPB, 2010). Along with these domestic tourism campaigns, each 
state's tourism promotional center also organized a state-focused traveling campaign to boost its tourism industry, for instance "Visit Selangor Year 2019", "Visit Melaka Year 2019", Visit Sarawak Year 2019, "Visit Johor Year 2020 " and etc.

\section{The Role and Function of Destination Logos}

According to Merve Senoymak Ersan and Birsen Ceken (2017), similar to organizations and companies, countries also use branding techniques to establish images, to be noticeable in the global marketplace, and to be known as an outstanding tourist destination. Yet, a strong country brand is important not only for tourism development but also to attract potential investors, factories, companies. Given that, a country's branding is no doubt a significant part of the infrastructure to foster any country's growth and long-term development. Leif $\mathrm{E}$. Hem and Nina M. Iversen (2010) also mentioned that the main goal of a logo is to enhance awareness about the destination and to build a beneficial destination image. Therefore, strong visual identity for destination branding plays a vital role and is a crucial tool in developing "the brand" for any country. Pietro Beritelli and Christian Laesser (2016) described that tourist destination branding has become a major element in tourism marketing. As such, a "destination logo" has a prominent role to play and becomes one of the most vital elements for a destination's brand communication and marketing campaigns.

Since the second half of the 20th century, the world witnessed tremendous growth and competition in the tourism industry. Given that, every city and country need to compete with each other for the economic advantages of tourism. Consequently, the concept and practice of destination branding were widely employed by different nation's tourism agencies to brand and market their countries as outstanding destinations for a vacation. For many, this has meant creating an appealing tourism logo that speaks to the hearts and minds of potential visitors from around the globe. Therefore, logo design for promoting a city, town, and country has become a phenomenon and given a name as "Destination logo" or "Tourism logo". These two terms are used interchangeably by scholars. Yet the term destination logo seems to be more widely used than the tourism logo.

Destination logo is generally known as a unique and memorable visual identity of a city or country in the global tourism market. Therefore, it is one of the most significant elements in creating a strong country brand. Moreover, a destination logo also plays a crucial role to establish and uphold a unique country identity to both local and international stakeholders. Similar to the concept of business logo, which serves as an identification and strategic tool of business, a destination logo is a visual and symbolic representation of a country's identity as well as a strategic tool of destination branding. Suman Lee, Lulu Rodriguez, and Sela Sar (2012) pointed out that the destination logo has a tremendous influence on country image, and people's perspectives toward the destination are significantly affected by the visual and message of the tourism logo. For instance, the "I Love New York" city logo designed by Milton Glaser in 1977 is a classic example of how a strong destination logo is able to brand a city outstandingly, moreover become a lasting icon for the city.

Today, the importance of the destination logo as a branding tool has become a popular strategy in the tourism industry. However, to create an outstanding destination logo that is able to succeed and last for a long period as I Love New York's city logo is rather challenging. As Marcus Osborn (2013) mentioned that a destination logo is a significant element of the destination identity, and should match the destinations they represent. Hence, it is difficult to create a strong destination logo, and ends up there are many destination logos with a similar "look". Furthermore, for destinations that are not just seeking tourists but also investors, talent, and strategic partners, a great logo that is able to attract, invite and inspire these key audiences is even more difficult to be accomplished. Considering that, it is not surprising to see that there are still many cities and countries in search of a "unique identity" to be featured in their destination logos.

In sum, the purpose of a destination logo is to establish a visual representation of a country. Therefore, an outstanding destination logo design should be unique, generate high impact, be memorable, and leave a positive impression. Meanwhile, a successful destination logo will also be effective in conveying a country's brand image and message. Faced with high competition in today's global tourism market, different nations' tourism agencies are constantly seeking strategies to differential their products and positioning. In this context, destination branding if successful can provide a point of differentiation allowing city and country to insulate themselves to some degree from competition. The destination logo as a strategic tool, therefore, has a crucial role to play for any country's destination's branding. 


\section{METHODS}

To fulfill the purpose of this research, a qualitative research approach was employed. The research was divided into three stages. (1) Data collection was gathered through secondary sources. The researcher conducted online research to collect Visit Malaysia's logo from the year 1990 to 2020. (2) After that, the researcher reviewed each logo's design based on its intellectual unity and visual unity. On the intellectual unity aspect, the subject matter of each logo was discussed, and on visual unity features, design elements such as logo style, visual representation, graphic elements, and colors selection were examined. (3). Upon the completion of the design review, the researcher reports the characteristics of each logo and identifies the opportunity and challenges of each logo is representing Malaysia's destination branding.

\section{RESULT AND DISCUSSION}

In 1990, along with the launching of the first Visit Malaysia Year's tourism campaign, the very first destination logo of Malaysia was introduced. Under the theme of "Fascinating Malaysia -Year of Festivals", the main visual representation of the logo is an image of Sultan Abdul Samad Building at the Dataran Merdeka (Independence Square) with a beautiful sunset standing above a ribbon-like graphic. At the side of the building is the image of "Bunga Manggar" (literally means the palm blossom of a coconut), an important decoration for auspicious occasions and ceremonies. The main text, "Visit Malaysia Year 1990" is presented together with the tagline "You will be fascinated". Meanwhile, the entire logo's color selection is mainly based on a mix of warm colors to position Malaysia as a warm and happy destination. Concept-wise, the design embodies the keywords "fascination" and "festivals" through (1) the representation of historical architecture Sultan Abdul Samad Building, (2) an local culture - Bunga Manggar, and (3) a beautiful nature with a warm sun.

In 1994, the second edition of the Visit Malaysia Year tourism campaign was promoted under the theme "Fasinating Malaysia. Naturally More", Similar to the previous logo, the Sultan Abdul Samad Building with a beautiful sunset continues to be key image of the 1994's logo design. Yet this version has removed the image of Bunga Manggar and the tagline. With a simpler graphic representation, the logo has a more focus on its overall visual quality. Moreover, this simplified version is probably to highlight the image of the "sun" as the key visual to echo the theme that emphasis on "Naturally More."

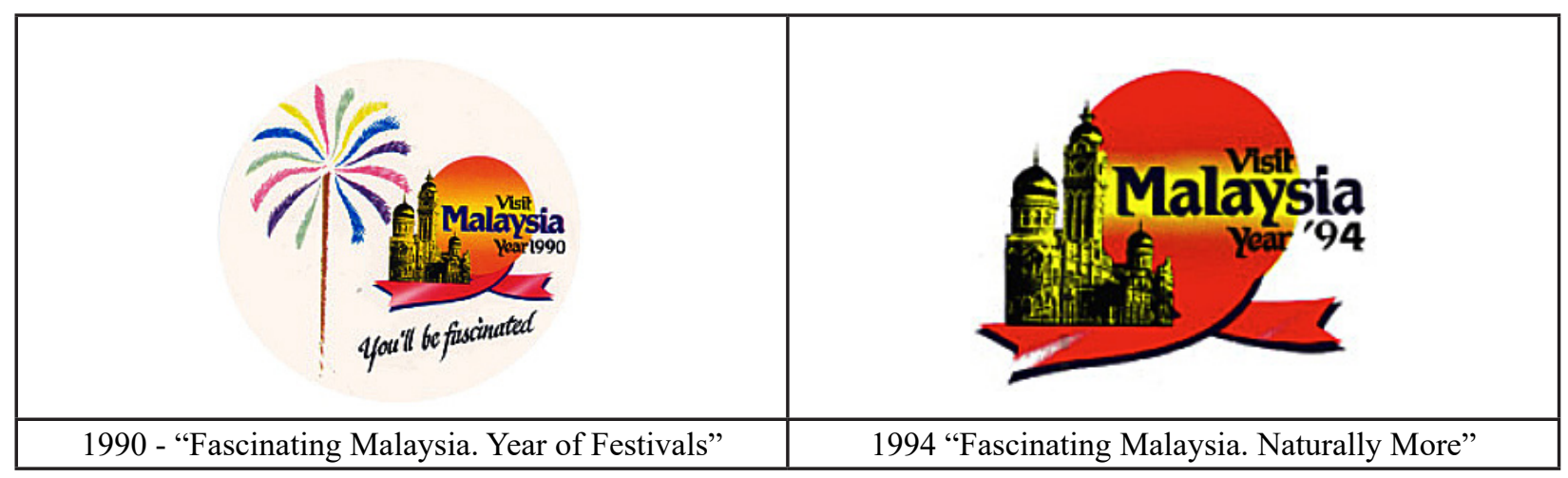

Figure 1. Visit Malaysia Year logos (1990 and1994)

Before the establishment of the Petronas Twin Towers in 1999, Sultan Abdul Samad Building at the Independence Square stands as the most prominent landmark to represent the image of Malaysia both locally and internationally. Therefore, it is not surprising to see this historical architecture has been selected as a key visual representation of Visit Malaysia Year's logo in 1990 and 1994. Furthermore, as the usual venue for the annual National Day Parade since 1957, Sultan Abdul Samad Building and the Independence Square serve a strong symbolic representation of Malaysia as an independent nation with its own identity, glory, and achievement. It is therefore considered to be an ideal image to promote Malaysia for both local and international tourism markets in the 1990s. 


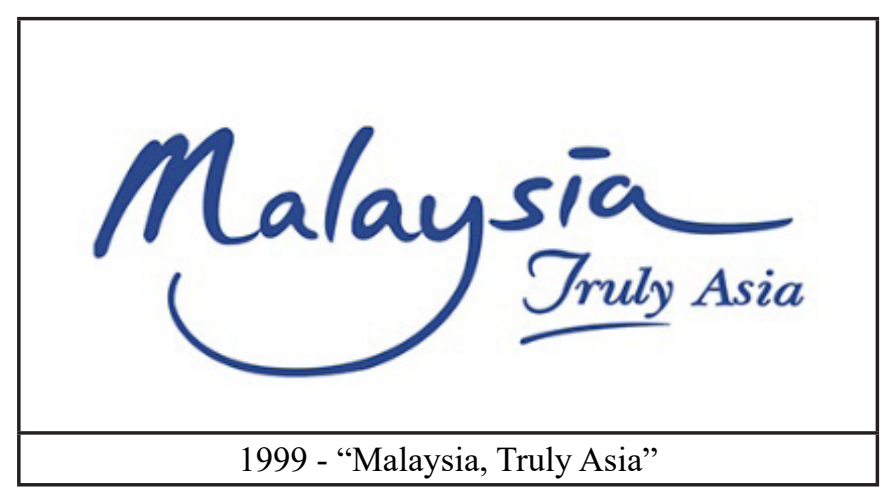

Figure 2. Visit Malaysia logo (1999)

In 1999, to celebrate the country's unique diversity as the theme of a new tourism campaign, the "Malaysia Truly Asia" campaign was launched. According to Malaysia Tourism Promotion Board (MTPB), Malaysia is the only one place where all the colors, flavors, sounds, and sights of Asia come together, no other country has Asia's three major races, Malay, Chinese, Indian, plus various other ethnic groups in large numbers. Therefore, no other county is "Truly Asia" as Malaysia (MTPB, 1999). The branding of Malaysia as "Truly Asia" received tremendous success and the nation has seen its annual tourists trebling since the millennial. Moreover, the campaign also successfully established Malaysia with a strong presence internationally. Given that, the slogan of "Malaysia Truly Asia" has become the most important "brand element" for all tourism campaigns that come after.

In terms of logo design, different from previous destination logos design, the "Malaysia Truly Asia" logo is a "wordmark" logo (also known as logotype). It is a font-based logo with a focus on the country's name and its slogan. The highlight of this logo is on the letter's "Malaysia", particularly of the design of the letter "y" that created a look like a smile. When combined with the rest of the letters, the entire logo reveals a very subtle resemblance to a smiling face. Research has shown that humans have incredible facial recognition and place a lot of trust in a smiling face. By designing the "Malaysia Truly Asia" logo to look like a smiling face, Malaysia is able to convey that the country is a trustworthy, friendly, and welcoming destination. For color selection, blue as a color that symbolizes trust, confidence, truth, and sincerity was chosen to showcase Malaysia's friendliness and trustworthiness.

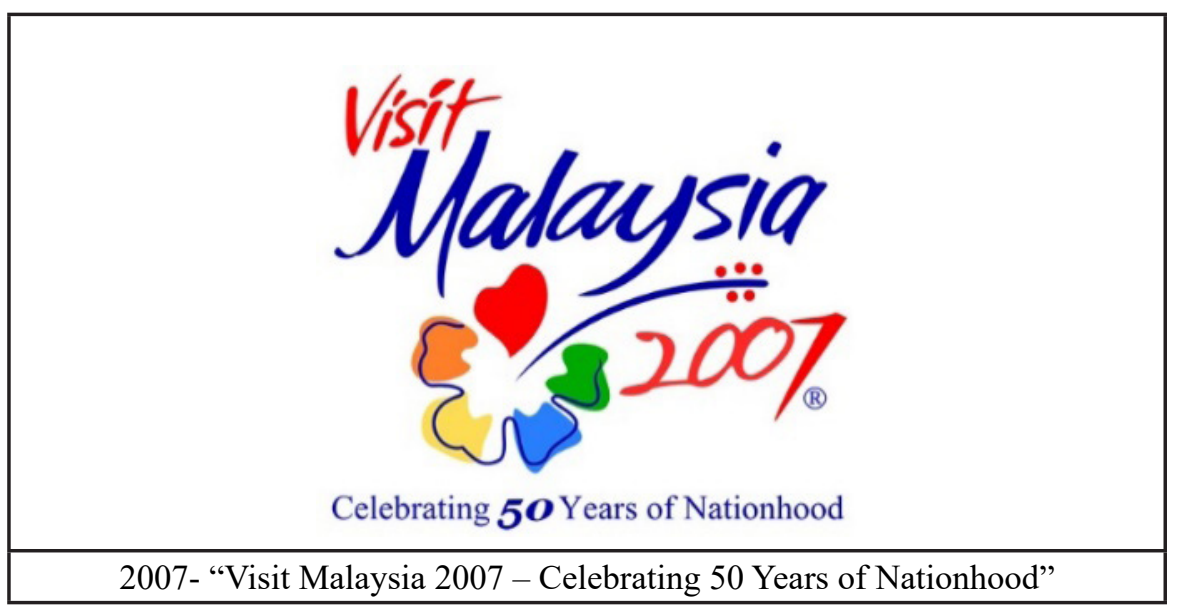

Figure 3. Visit Malaysia Year logo (2007)

In 2007, the "Visit Malaysia Year" returned for its third edition in conjunction with the nation's celebration of 50 years of nationhood. To highlight the theme of "Visit Malaysia 2007 - Celebrating 50 Years of Nationhood", a new logo was introduced to commemorate the national celebration of the 50th anniversary and serve as a new identity of the third Visit Malaysia Year campaign. The design of this logo is revolving around the keyword of "celebration". In terms of visual representation, a hibiscus motif is the highlight of the logo. It is a wise-chosen design element as the hibiscus is a very meaningful flower to represent Malaysia.

In 1960, the hibiscus (known as Bunga Raya in Malay) was declared by the government of Malaysia as the national flower. As Sandra Low (2018) described that the word Bunga in Malay means "flower", while Raya in Malay means "celebratory" or "grand", so the hibiscus is literally known as the "celebratory flower" in Malay. Meanwhile, the five petals represent the "Five National Principles of Malaysia" and the red of the petals 
also symbolizes courage, life, and the rapid growth of the Malaysian. In terms of color selection, the petals of Bunga Raya were filled with five dynamic multi-colors namely red, orange, yellow, blue, and green to showcase and celebrate the country's multicultural identity as well as promote Malaysia as a destination full of love and friendliness. Given that, a heart shape hibiscus petal right in the middle of the whole visual identity serves as the key graphic element to illustrate the concept mentioned above.

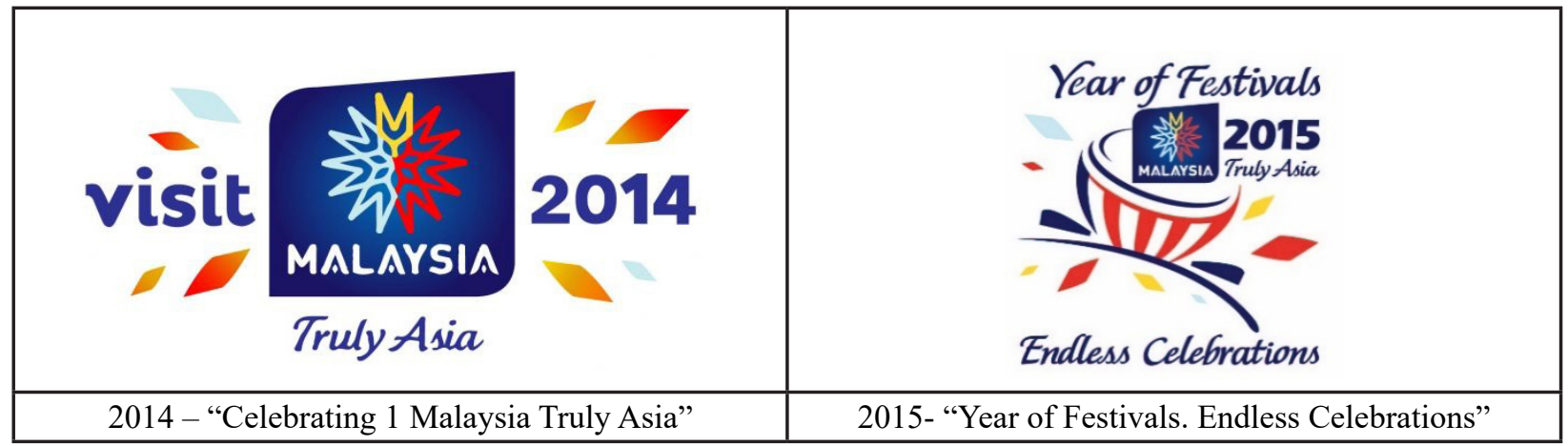

Figure 4. Visit Malaysia Year logo (2014 and 2015)

In 2014, with the theme "Celebrating 1Malaysia Truly Asia" to reflect the diversity in unity of all Malaysians, Malaysia celebrated its fourth edition of Visit Malaysia Year with a brand-new campaign. Once again, a new Visit Malaysia Year logo was launched, and the iconic slogan "Truly Asia" has once again returned the highlight of the campaign's communication. For the 2014's logo, the visual representation is centered around the concept of "one Malaysia with united in diversity". Similar to the graphical elements showcased in the national flag, an abstract 14-point star-like graphic (formed by letter "M") that illustrated Malaysia as the federation of the 13 member states and the federal territories are the highlight of the 2014's logo. Meanwhile, four symbolic colors of Malaysia's flag namely blue, red, white, and yellow were also presented in this logo. Compared to previous Visit Malaysia Year's logos, this logo is considered to be most "nationalistic" as the design utilized all symbolism of the nation's flag. It is no doubt a patriotic logo that was strategically selected to echo the "1Malaysia" national campaign which emphasis on promoting ethnic harmony, national unity, and efficient governance at the period.

In 2015, following the great success of Visit Malaysia Year in 2014, the tourism campaign continues to promote Malaysia as a premier destination for a vacation. As a result, a new theme of "Year of Festivals. Endless Celebrations" was launched to position Malaysia as a destination with endless festival celebrations. Considering that, key visual elements of the 2014 logo such as the 14-point star-like graphic were incorporated into the 2015's logo. Yet, a new visual element - a "Rebana" (Malay tambourine) was added to illustrate the key message, "endless festival celebration". Once again, symbolic elements from Malaysia's flag were utilized in this logo, the graphic of the Rebana was designed based on the red and white stripes of the nation's flag which represent the equal status in the federation of the 13 member states and the federal territories. Color-wise, similar to 2014's design, four

In sum, since the fourth edition of the Visit Malaysia Year campaign to present, the iconic "Malaysia, Truly Asia" tagline has regained its significant position in Malaysia's destination logos. Although from time there are selected keywords and graphics presented on the nation's destination logos, "Malaysia, Truly Asia" has no doubt the key message that cannot be neglected.

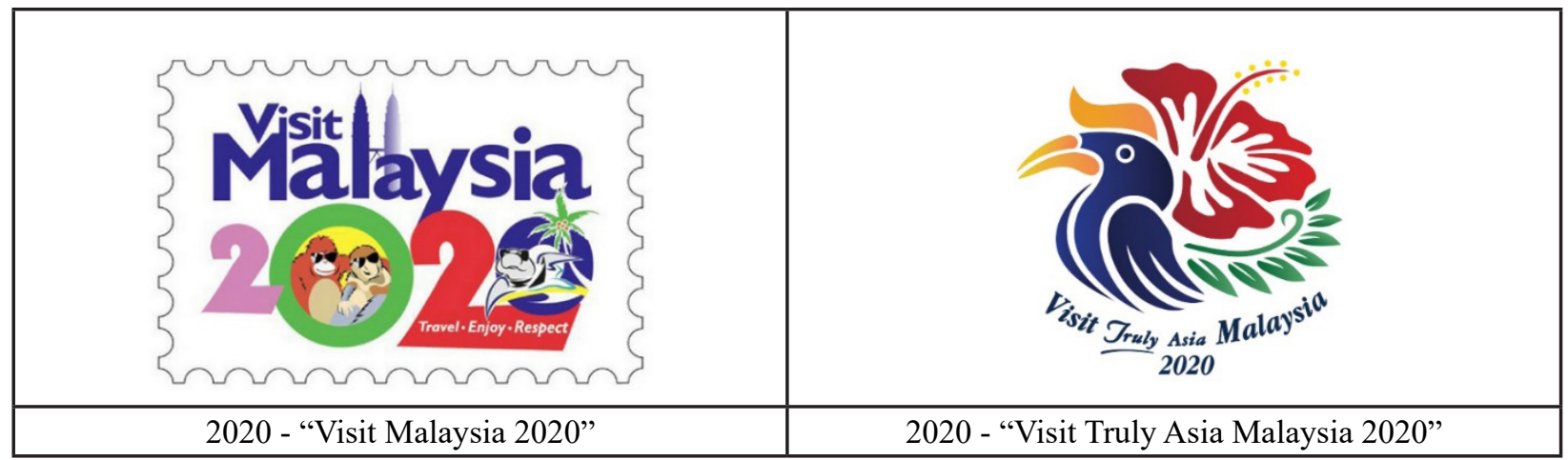

Figure 5 Visit Malaysia Year logo (2020) 
In January 2018, the Tourism Ministry of Malaysia unveiled the "Visit Malaysia 2020" logo at the ASEAN Tourism Forum 2018 at Chiang Mai, Thailand. Straight after the news was released, the logo has been mocked by netizens for its poor design, and many are wondering how can the authority approve to have such a "hideous" and "embarrassing" logo to represent Malaysia internationally. Moreover, the tagline "Travel. Enjoy. Respect", was copied from the World Tourism Organization (UNWTO)'s 2017 slogan for sustainable tourism. Many netizens also pointed out how "ugly" the logo looks when compared to the designs from previous Visit Malaysia campaigns. As reported by Greg Dickinson (2018), on social media, critics were slamming the Visit Malaysia 2020 tourism logo as "hideous", "a joke" and an "insult to all professional graphic designers" for its retro imagery and mismatched font sizes. Although the authority has defended the logo and tried to justify the logo as "problemless", the justification was not able to hide the mediocrity of the logo.

The Branding expert Marcus Osborne (2018) pointed out; the logo looks like an irresponsible adult allowed a petulant child with a grudge against the creative fraternity loose on an ancient software program. It should never have made it past the idea stage. It's the creative equivalent of a train crash featuring trains carrying toxic chemicals or nuclear weapons. Zayn Khan (Southeast Asia CEO of Dragon Rouge) in his interview with Malaysia Marketing Interative.com mentioned that if benchmark the logo against what competitor markets such as Singapore, Thailand, Indonesia, and Hong Kong are doing, it is not even in the same league. Thus, visitors will likely be turned off by this kind of Visit Malaysia 2020 theme. Meanwhile, Casey Loh, (Creative chief of The Clan) also said that the logo is a poor representation of the large pool of talent Malaysia has (Marketing Interactive. com, 2018). Since its release, an online petition has been set up calling for Tourism Malaysia to stop using the design. More than 8,000 people have backed the campaign. More productively, graphic designers of social media have responded to the logo with some recommendations of their own. (Greg Dickinson, 2018). Consequently, alternative versions of the logo have been circulating online, with many netizens commenting that there are all better designs than what the Tourism Ministry has produced.

In July 2018, in response to the public criticism of the 2020 visit Malaysia logo design for being poorly designed and unprofessional, the Tourism Ministry is planning to seek for a new design. In March 2019, a nationwide logo competition was launched to call upon all Malaysian creative talents to participate. Finally, in July 2019, from hundreds of submissions nationwide, a winning logo was chosen. The new logo was the work of 23-year-old graphic designer Alfred Phua Hong Fook from Malacca. In terms of concept and design, the new logo no doubt is far much presentable than the previous one. Inspired by Malaysian batik (traditional wax painting) motif design, the logo features various distinguishable national icons such as the Rhinoceros Hornbill, the red hibiscus (Bunga Raya), the wild fern (Paku-pakis), and three colors of the Malaysian flag. Together, they represent the diversity of Malaysia's culture, heritage, flora and fauna as well as experiences offered as a holiday destination (Hashini Kavishtri Kannan, 2019).

Rachel Genevieve Chia (2019), netizens have since affirmed that Phua's logo is a marked improvement over the previous one. However, the new logo is still not exempt from ridicule, as people have since taken issue with its slogan, which reads: "Visit Truly Asia Malaysia 2020", not as "Malaysia, Truly Asia". Don Carter (2019) also pointed out that, the new logo's slogan is difficult to read. When reading from left to right, the message appears to be "Visit Truly Asia Malaysia". Yet, when you take into account that the logo uses two different fonts, it suddenly clicks in place to read "Visit Malaysia, Truly Asia". Meanwhile, some netizens also pointed out that the new logo has high similarities to vector graphics found across the web. In the report of the Malay Mail.com, the VMY2020 logo was alleged to have not only had a grammatical error on its slogan but also been copied and modified from one of Shutterstock graphic designs, with these allegations once again the Visit Malaysia Year's logo topic went viral on social media (MalayMail.com, 2019). In response to netizens' criticism, Culture, Arts and Tourism Minister Datuk Mohamaddin Ketapi said the usage of the English language in the logo was correct and said only those who were not well-versed with the language would deem the phrasing as wrong. Meanwhile, on allegations that the logo was plagiarized, he mentioned that the new logo was completely original. Citing to the 23-year-old designer who is a first-class degree holder would not humiliate himself by copying other people's work (Hafizah Iszahanid, 2019). Currently, the new logo has been officially used on all official media and communication of Tourism Malaysia and the fifth edition of "Visit Malaysia Year 2020" was launched in January 2020. 


\section{CONCLUSION}

In sum, from 1990 to 2020, five editions of Visit Malaysia Year tourism campaigns have been executed, and eight different version destination logos have been created along with the theme of each campaign. Under the theme "Fascinating Malaysia - Year of Festivals" in 1990 and "Fascinating Malaysia -Naturally More in 1994, the two logos' main visual element is the historical architecture - Sultan Abdul Samad Building. The reason why the two logos used the image of this building to brand Malaysia as a fascinating destination is probably because of its historical and cultural significance. In 1957, the ceremony of Malaya gained independence to take place in front of the Sultan Abdul Samad Building. Furthermore, since January 1990, the building and its compound were renamed Dataran Merdeka (Independence Square) and serve as an official location for the Independence Day celebration each year on August 31. Therefore, it is not surprising to see the image of the building was utilized by Malaysia Tourism Promotion Board as the key visual of the first and second edition of the Visit Malaysia Year campaign's logo. In brief, the image of Dataran Merdeka is a suitable key visual to promote Malaysia's tourism in the 1990s. Yet, to view the logo along with its slogan of "Fascinating Malaysia -Naturally More" campaign in 1994. Apparently, the "Naturally More" message is hard to be perceived. Considering that, the 1994's campaign logo no doubt has its limitation in unifying the subject matter with its visual representation.

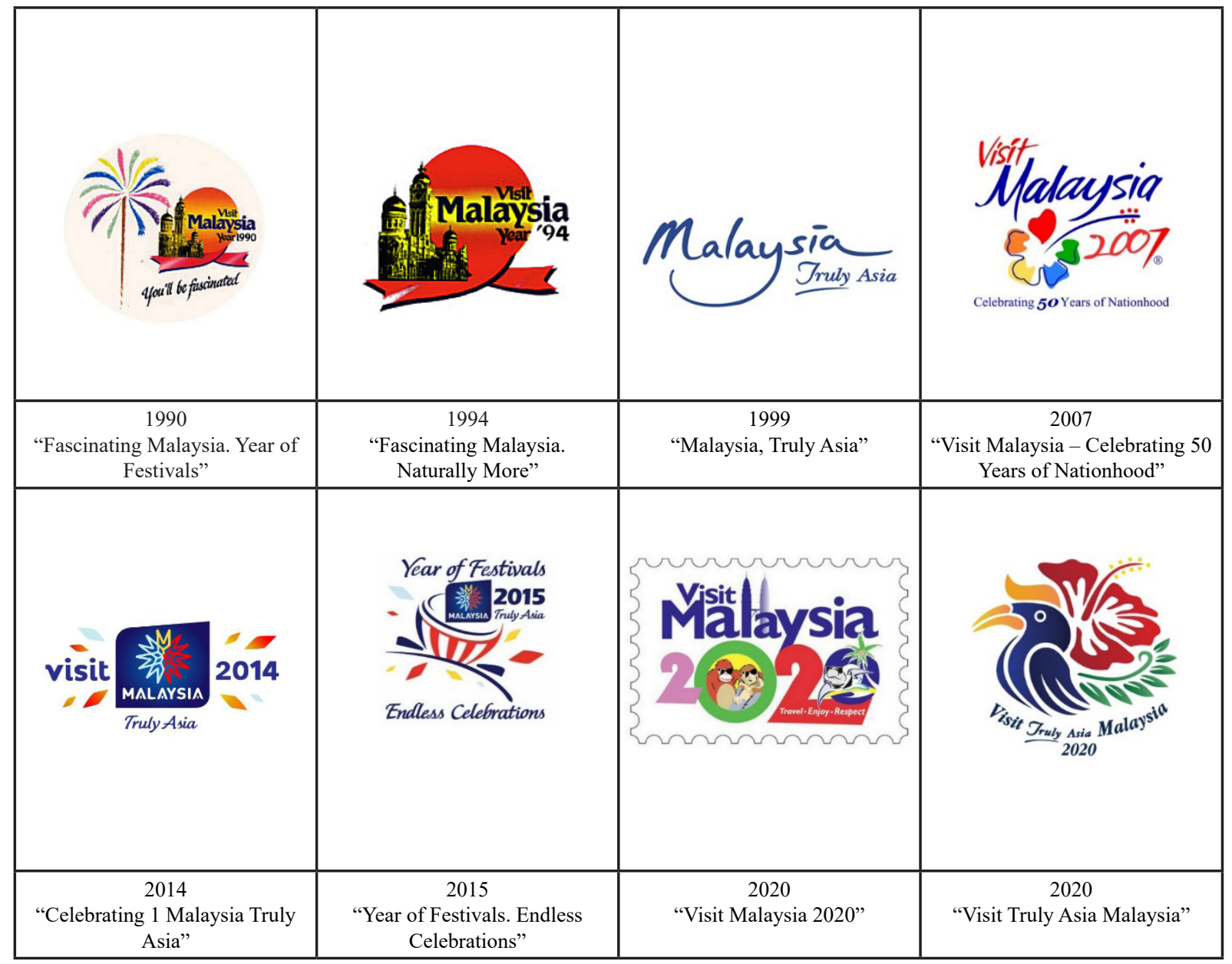

Figure 6 Malaysia's Destination logos (1990 - 2020)

In 1999, with the new theme of "Malaysia Truly Asia," a new logo was also launched to promote Malaysia's tourism. Different from previous logos' design, the Truly Asia campaign's logo is a wordmark logo. The word Malaysia was designed to look like a smiling face to represent Malaysia as a hospitable destination. The "Malaysia - Truly Asia" positioning is based on the country's unique multicultural context. It sums up Malaysia's remarkable achievement in celebrating cultural diversity and social harmony. The logo as such was designed to resemble a smiling face to mirror Malaysia's distinctive accomplishment is founded on its people's friendliness and tolerant nature. With the success of this campaign, from 1999 to the present, the slogan of "Malaysia Truly Asia" has become the key destination branding's message for Malaysia. 
In 2007, in conjunction with the nation's celebration of 50 years of nationhood, the third edition of Visit Malaysia Year was launched. Compared with other logos from Visit Malaysia Year campaigns, the 2007 logo serves not merely as a visual of celebrating Malaysia as an interesting tourist destination, it is also a symbol to commemorate the country's 50 years of nationhood. In 2014, a new slogan, "Celebrating 1Malaysia Truly Asia" was given to the fourth edition of the Visit Malaysia Year campaign. Similar to the third campaign's logo, the logo of the fourth also served not only as a symbol of destination branding, yet it is also echoed to "1Malaysia" national campaign's theme in promoting nation's interest, particularly on ethnic harmony and national unity. In 2020, the fifth edition of Visit Malaysia Year was launched. Along with the campaign, a new logo was introduced to replace the one previously unveiled by the Tourism Ministry of Malaysia at the ASEAN Tourism Forum at Chiang Mai in 2018. The new slogan of "Visit Truly Asia Malaysia" was once again celebrated Truly Asia as the keyword in promoting Malaysia. For the campaign's logo, the 2020's version is also very different from previous designs. It is the first time to see both natural and cultural elements are features in Malaysia's destination logo. The design showcase the nation's flora and fauna in a style of Malaysia batik, it is a logo that emphasizes on Malaysia as a destination of rich culture and natural heritage.

By and large, over a period of three decades, the destination logo's design of Malaysia changed along with the given theme of each campaign. Apart from the 2018 version that has been mocked by netizens for its poor design. Other campaigns' logo is considered to be presentable in showcasing Malaysia as a distinctive tourist destination. Yet, the most outstanding design, no doubt is the 1999 "Malaysia - Truly Asia" logo. The logo exceptionally features Malaysia's remarkable achievement in multi-ethnic harmony and national unity through the smile of each Malaysian. The slogan design is also strongly conveying the message of Malaysia as the mosaic of multi-cultural integration.

In conclusion, in this research, the researcher attempted to examine Malaysia's destination logos' design from 1990 to 2020. As with the majority of studies, the study is subject to limitations. First, the study focused on only eight logos from five editions of Visit Malaysia Year tourism campaigns. Second, the discussion is only limited to logos' design particularly on intellectual unity and visual unity. For future research, a wider scope of design context and sample will be useful to deeper the discussion of the subject.

\section{REFERENCES}

Bernama News. (2019, October 11). Malaysia ranks first in global Muslim travel index. Retrieved from https:// www.nst.com.my/news/nation/2019/10/528969/malaysia-ranks-first-global-muslim-travel-index.

Beritelli, Pietro., Laesser, Christian. (2016). Destination logo recognition and implications for intentional destination branding by DMOs: A case for saving money. Retrieved from https://www.sciencedirect.com/ science/article/pii/S2212571X1630214.

Carter, Dom. (2019, July 24). Improved Visit Malaysia 2020 logo still has a glaring error. Retrieved from https:// www.creativebloq.com/news/new-visit-malaysia-2020-logo-ditches-stoner-orangutans.

Chia, Rachel G. (2019). Netizens love the new Visit Malaysia 2020 logo, but are now hating on the new slogan. Retrieved from https://www.businessinsider.my/netizens-love-the-new-visit-malaysia-2020-logo-butare-now-hating-on-the-new-slogan.

Chin, C. (2019, November 27). Malaysia welcoming more tourists in the lead-up to VM2020. Retrieved from https://www.thestar.com.my/lifestyle/travel/2019/11/27/malaysia-welcoming-more-tourists-in-the-lead-up-to-vm2020.

Dass, F. (2017, April 6). New Straits Times - Malaysia ranked 26th most Competitive Tourism Destination by WEF. Retrieved from https://www.nst.com.my/news/2017/04/227737/msia-ranked-26th-most-competitive-tourism-destination-wef.

Dickinson, Greg. (2018, January 30). Malaysia tourist board ridiculed for 'hideous' new logo. Retrieved from https://www.telegraph.co.uk/travel/destinations/asia/malaysia/articles/malaysia-tourist-board-logo-ridiculed.

Ersan, Merve Şenoymak., Ceken, Birsen. (2017, October). Country Brands: A Typographic Analysis of Tourism Logos. Retrieved from https://www.researchgate.net/publication/320927230_Country_Brands_A_Typographic_Analysis_of_Tourism_Logos. 
Hanaffi, F. (2019, January 6). Malaysia Ranked the Third Most Popular Asian Travel Destination in 2018. Retrieved from https://www.worldofbuzz.com/malaysia-ranked-the-third-most-popular-asian-travel-destinationin-2018/

History - Ministry of Tourism, Arts and Culture Malaysia. (2021, January 7). Retrieved from http://www.motac. gov.my/en/profile/history.

Hem, Leif E., Iversen, Nian M. (2010, November 16). How to Develop a Destination Brand Logo: A Qualitative and Quantitative Approach. Retrieved from https://www.tandfonline.com/doi/ abs/10.1080/15022250410003852.

Iszahanid, Hafizah. (2019, July 23). Only those not well-versed in English will find VM2020 tagline wrong. Retrieved from https://www.nst.com.my/news/nation/2019/07/506655/only-those-not-well-versed-englishwill-find-vm2020-tagline-wrong.

Kannan, Hashini K. (2019, July 22). New VMY2020 logo unveiled. Retrieved from https://www.nst.com.my/news/ nation/2019/07/506262/new-vmy2020-logo-unveiled.

Lee, Suman., Rodriguez, Lulu. \& Sar, Sela. (2012). The influence of logo design on country image and willingness to visit: A study of country logos for tourism. Retrieved from https://www.sciencedirect.com/sciencel article/abs/pii/S0363811112001348.

Low, Sandra (2018, August 29). Six beauty products honouring the hibiscus, Malaysia's national flower. Retrieved from https://www.msn.com/en-my/lifestyle/lifestylegeneral/6-beauty-products-honouring-the-hibiscus-malaysia's-national-flower/ar-BBMCYJa.

Malaysia Economy Report. (2018). Economic Performance and Prospects. Retrieved from https://www.treasury. gov.my/pdfleconomy/er/1718/chapter3.pdf.

Malaysia Tourism Promotion Board. (2020). Visit Malaysia Year Tourism Campaign. Retrieved from https://www.tourism.gov. my/campaigns/view/visit-malaysia-year

Malaysia Tourism Promotion Board. (2019, August 15). Domestic Tourism Performance 2018. Retrieved from https://www. tourism.gov.my/media/view/domestic-tourism-performance-2018.

Malaysia Tourism Promotion Board. (2014, November 3). Visit Malaysia Year. Retrieved from https://www.tourism.gov.my/ campaigns/view/visit-malaysia-year.

Malaysia Tourism Promotion Board. (2010, November 3). The Zoom! Malaysia. Retrieved from https://www.tourism.gov. my/campaigns/view/zoom-malaysia.

Malaysia Tourism Promotion Board (1999). Malaysia Truly Asia. Retrieved from https://www.tourism.gov.my/campaigns/ view/malaysia-truly-asia.

MalayMail.com (2019, July 23). Tourism minister says Visit Malaysia Year 2020 logo original, dismisses 'grammatical error'. Retrieved from https://www.malaymail.com/news/malaysia/2019/07/23/tourism-minister-laughs-off-claims-visit-malaysia-year-2020-logo-copied/1774196.

Osborn, Marcus. (2013). How important is a logo in the destination branding process? Retrieved from https:// brandconsultantasia.com/2012/03/20/how-important-is-a-logo-in-the-destination-branding-process/.

Osborn, Marcus. (2018, February 23). Six Lessons on How to Avoid Malaysia's Tourism Logo Disaster. Retrieved from https://www.brandinginasia.com/six-lessons-avoid-malaysias-tourism-logo-disaster/.

Tan, Janice. (2019, July 26). Tourism a 'Major Contributor' to Malaysia's economic success. Retrieved from https://www.marketing-interactive.com/tourism-a-major-contributor-to-malaysias-economic-success/. 